\title{
Student Motivation to Study Abroad and Their Intercultural Development
}

\author{
Philip H. Anderson \\ University of St Thomas
}

Ann Hubbard

American Institute for Foreign Study

Leigh Lawton

University of St Thomas

\section{Introduction}

Between 1997 and 2007, the number of US students choosing to study abroad for academic credit grew from under 100,000 to nearly 250,000 (Stroud, 2010). This growth has continued to nearly

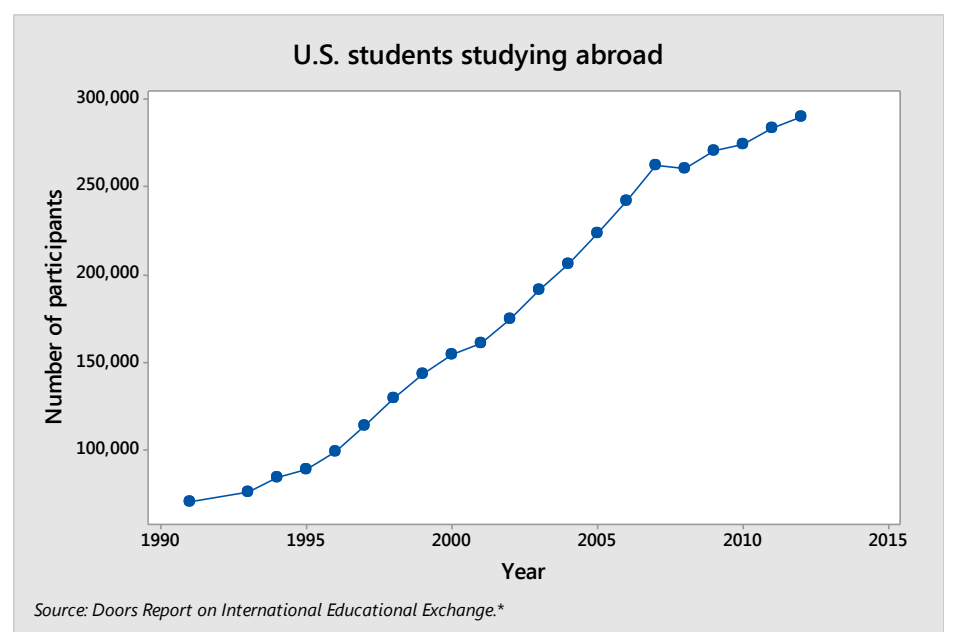
274,000 during the 2010-2011 academic year (The Institute for International Education, 2012) and 283,332 in the 2011-2012 academic year (The Institute for International Education, 2013). Given this historical trend, the number of US students studying abroad is expected to increase. In fact, an initiative by the Institute for International Education Generation Study Abroad, launched in 2014 , has a goal of 600,000 by the 2017 18 academic year (http://www.iie.org/Programs/GenerationStudy-Abroad).

Students and their parents believe studying abroad enhances career prospects in terms of securing interviews, receiving job offers, and accelerating career progression (Franklin, 2010; Stroud, 2010). And for educational institutions, these programs serve as a recruitment tool for prospective students. Increasingly, students base their college selection on study abroad opportunities as well as academic offerings and campus life considerations (Internationalization of US Higher Education, American Council on Education Report 2000).

Because study abroad programs divert resources that otherwise could be allocated to on-campus programs, measuring simple participation rates in study abroad programs is an insufficient basis for justifying their success (Vande Berg, 2001). More comprehensive assessments of study abroad programs are required to ensure they achieve educational goals that enhance the skills essential for operating effectively in an increasingly complex global environment (Earnest, 2003; Gillespie, 2002). Hard evidence is needed that the study abroad experience translates into the global awareness and intercultural competence valued by students, employers, and educators (Stebleton, Soria and Cherney, 2012-2013). Indeed, assessing whether these programs are preparing students to live and work in an ever more interdependent global environment has become part of the accreditation process (Higher 
Learning Commission, 2012 and 2007; AACSB International Eligibility Procedures and Accreditation Standards for Business Accreditation, 2012).

\section{Literature Review}

Bennett (2011) defines intercultural competence as "a set of cognitive, affective, and behavioral skills and characteristics that supports effective and appropriate interaction in a variety of cultural contexts" (Bennett, 2011, p. 4). While there is broad, general agreement on the definition and the need to incorporate intercultural competence into students' study abroad experience, there is continuing debate over how best to assess, and what factors most influence, intercultural development (Stebleton, Soria and Cherney, 2012-2013; Braskamp, Braskamp, \& Merrill, 2009).

\section{Measuring Intercultural Competence}

Kelly (1963) argues that a person can witness an event without ever experiencing it (p. 73), so simple exposure to a culture may not be sufficient to guarantee improved cultural awareness. Rather, developing intercultural competence is likely to be a function of one's ability to categorize events appropriately. Instruments designed to measure cultural awareness, such as the Intercultural Development Inventory (Hammer and Bennett, 2002) and Global Perspectives Inventory (Braskamp, Braskamp, \& Engberg, 2013) purport to incorporate this premise into the factors they measure.

While appropriate measurement instruments are critical to the assessment of study abroad programs, the aim of this study was not to evaluate the merits of alternative instruments. Rather, we focused on analyzing the relationships between the motivations underlying students' decision to study abroad and their intercultural development.

We chose to use the Global Perspectives Inventory (GPI) based on a review conducted by researchers at Michigan State University (Roy, Wandschneider, \& Steglitz, 2014). Among its strengths, they cited its being "based in student development theory ... uniquely suited for assessment at the undergraduate level” (p. 8). Since all of our subjects were undergraduate students, the GPI is an appropriate instrument for this research. Further, the GPI allows for cross-institutional comparisons of norms based on data from 42,000 students at higher education institutions.

\section{Study Abroad and Intercultural Development}

Although there are exceptions (Paige \& Vande Berg, 2012), a review of the literature finds support for a relationship between student participation in study abroad programs and intercultural development (defined as the change in intercultural competence following a study abroad experience). For example, Paige, Cohen, and Shively (2004) report evidence that study abroad has a positive impact on intercultural development. As part of the Georgetown Consortium Project, Vande Berg, ConnorLinton, and Paige (2009) found study abroad participants' pre-post gains in intercultural development were significantly greater than a control group of students (p. 18). Anderson and Lawton (2012) found similar results for a faculty-led, semester-length program. Again, students in the study abroad program demonstrated greater gains in intercultural competence than did a "pseudo control" group of students studying on campus during the same semester.

More recently, Stebleton, Soria and Cherney (2013) reported that participation in study abroad was positively associated with the ability of students to understand the complexities of global issues, to apply disciplinary knowledge in a global context, to develop linguistic and cultural competency in 
another language, and to work with people of other cultures.

As stated by Vande Berg, et al., (2009), there is strong support that "study abroad programs can provide important opportunities (emphasis added) for increasing intercultural competence (p.18). But, as discussed below, the focus of their research, extended beyond the effect of just immersion to include factors that influence intercultural learning. As stated by Bennett (2010), to maximize the potential for intercultural learning, there is a need for "facilitation"; that learning "does not therefore occur automatically" (p. 19).

\section{Factors Related to Intercultural Development}

Consequently, more recent research has focused on factors that influence the intercultural development of students who study abroad. A number of pre-post studies have reported on students' demographics and experiences while studying abroad and their intercultural development. For example, Paige, Cohen, and Shively (2004) and Engle and Engle (2004) found that US students studying language in French and Spanish-speaking countries improved overall cross-cultural sensitivity. They also found the length of the study abroad program to be positively related to intercultural development. Rexeisen and Al-Khatib (2009) and Medina-López-Portillo (2004) reported that gender was related to intercultural development.

One of the most extensive and comprehensive assessments of factors related to intercultural development was the Georgetown Consortium Project, a multi-year study conducted by Vande Berg, et al., (2009). Their study looked at seven "defining components" that could impact intercultural development. The findings showed support for gains in intercultural competence, but that these gains were moderated by variables such as length of the study abroad experience, extent to which the students were immersed in the local culture while abroad, and presence of a "cultural mentor" abroad. However, they also reported that "a sizable number of students abroad did not learn significantly more than control students" (p. 25). They found that simple immersion was insufficient for the development of intercultural development. An intervention strategy, particularly cultural mentoring, was needed to ensure intercultural learning.

\section{Student Motivations and Intercultural Development}

To date, student motivation for electing to study abroad has not been incorporated into study abroad research as a potential factor influencing intercultural competence. We suspect that this omission may be a critical shortcoming of existing research. We hypothesize that a student's motivation for studying abroad plays an important role in influencing the program a student selects and in determining what that student gets out of that experience. We know from prior research that the nature and location of a program is related to students' intercultural development (Vande Berg, et al., 2009). But we don't know what motivates students to study abroad or to choose a more challenging study abroad experience. Do student motivations influence the type of study abroad program (e.g., faculty-led, immersion vs "island" programs) or the location of the program (e.g., English-speaking, Western Europe vs. Asia)?

Knowing what students seek to gain from their study abroad experience and its influence on program selection should provide guidance on how to design study abroad programs to best facilitate a student's intercultural development. That is, programs in more challenging locations could be 
presented in a fashion that makes it easier for students to see how it meets their goals (motivations) for studying abroad. If students find a good match between their study abroad goals and the program they choose, we anticipate that the opportunity for intercultural development is enhanced. It seems likely that if a student is comfortable with a program's features and location he or she will be more likely to seek deeper immersion into the culture. For this reason, we included student motivations in this study; we hoped to find relationships that could guide program providers and faculty in developing study abroad programs that can maximize the opportunity for student intercultural development.

\section{The Study}

The study, conducted over two academic years (2012-13 and 2013-14), employed a pre-post assessment of students participating in American Institute for Foreign Study (AIFS) programs. The goal was to assess the relationship between why students chose to study abroad, their choice of a program, and their intercultural competence. (AIFS is a provider of study abroad programs that works with educational institutions to organize the logistical and educational support needed to achieve desired educational goals and to facilitate students' intercultural development.)

\section{Methodology}

\section{Subjects}

The 355 students in this study came from colleges and universities across the US. As is the case with almost all study abroad programs, the vast majority of the students were women (84\%). The respondents' study abroad programs were located in 14 different countries and 19 different AIFS Program Sites. The programs included:

- Direct-enrollment at national universities of the host country and courses with indigenous students.

- Enrollment in courses designed for all international students (i.e., students outside the host country)

- Enrollment in courses designed for US students only

The students stayed in accommodations that included homestays, student apartments shared with other US students, and integrated dormitory living. The language of instruction included both English and non-English programs - programs were designated as non-English when all or most of the courses were taught in the host country's language and as English when the primary language of instruction was in English, including those programs in a non-English speaking location.

\section{Instruments Used}

\section{Global Perspective Inventory}

Assessment of the students' intercultural development was made by conducting pre-post measures using the Global Perspective Inventory (GPI) developed by Braskamp, Braskamp, Merrill, and Engberg (2010). They define a global perspective as the disposition and capacity for a person to think with complexity taking into account multiple perspectives (the cognitive dimension of global learning and development), to form a unique sense of self that is value based and authentic (the intrapersonal dimension), and to relate to others with respect and openness especially with those who are not like her (the interpersonal dimension) (p. 8). 
The GPI has been used extensively with college students. It is constructed to measure how people gain insight into the world around them, and how these insights influence their self-perception and interpersonal relationships. Further, Roy, Wandschneider, and Steglitz (2014) identified the GPI's ability to measure cultural understanding and a student's ability to critically analyze the complexity and interconnectedness of global processes (p. 11).

The GPI has six scales described in Exhibit 1. The GPI has established validity measures for the instrument's ability to assess respondents' intercultural competence (Braskamp, et al., 2013).

\section{Exhibit 1. Description of GPI Scales *}

Cognitive Domain Scales

- Knowing. Complexity of one's view of knowledge and the importance of cultural context in judging what is important to know and value.

- Knowledge. Degree of understanding and awareness of various cultures and their impact on our global society; proficiency in more than one language.

Intrapersonal Domain Scales

- Identity. Level of awareness of unique identity and degree of acceptance on one's ethnic, racial, and gender dimensions of one's identity.

- Affect. Level of respect and acceptance of cultural perspectives different from one's own and degree of emotional confidence when living in complex situations.

Interpersonal Domain Scales

- Social Interactions. Degree of engagement with others who are different from oneself and degree of cultural sensitivity in living in pluralistic setting.

- Social Responsibility. Level of commitment of interdependent living and the "common good".

*Global Perspectives Inventory (GPI): Its Purpose, Construction, Potential Uses, and Psychometric Characteristics, Braskamp, Braskamp, \& Engberg (2013). https://gpi.central.edu/supportDocs/manual.pdf. Retrieved 8-11-14.

\section{Motivation to Study Abroad.}

Assessment of students' motivations for studying abroad was done using the Motivation to Study Abroad (MSA) instrument developed by Anderson and Lawton (http://www.forumea.org/trainingevents/annual-conference/archive). The MSA is a set of 23 questions designed to measure factors that underlie a student's decision to study abroad. It has undergone extensive testing with students participating in study abroad programs. Factor analysis shows that it consistently measures four dimensions that impact a student's decision to study abroad. These are (1) world enlightenment (that is, learning about the world), (2) personal growth, (3) career development, and (4) entertainment. Exhibit 2 gives some examples of the items used for each of the four dimensions.

Exhibit 2. Motivation to Study Abroad

\begin{tabular}{|c|c|}
\hline \multicolumn{2}{|c|}{ World Enlightenment } \\
\hline$\bullet$ & Learn about the world \\
\hline • & Interact with people from other countries \\
\hline \multicolumn{2}{|c|}{ Personal Growth } \\
\hline • & Increase my self-confidence \\
\hline$\bullet$ & Gain maturity \\
\hline & elopment \\
\hline
\end{tabular}




\begin{tabular}{|ll|}
\hline$\bullet$ & Enhance my employment prospects \\
Entertainment \\
- & Gain in-depth knowledge in my chosen field \\
- & Have a romantic encounter \\
\hline
\end{tabular}

\section{Research Hypotheses}

Our focus for this research was to assess the influence of students' motivations for studying abroad on their intercultural development. Therefore, our main hypotheses are the following.

H1: $\quad$ The choice of a program destination will be associated with the student's motivation for studying abroad. We anticipate that students seeking entertainment will choose "less challenging" destinations than those motivated by a desire for world enlightenment.

H2: $\quad$ Students' post-GPI scores will be higher than their pre-GPI scores on the six dimensions of the GPI.

H3: $\quad$ Students having world enlightenment goals as their reason for participating in a study abroad program will demonstrate greater overall intercultural development as measured at the conclusion of the semester (pre-test to post-test) than those who participate to satisfy entertainment goals.

H4: $\quad$ Students having personal growth goals as their reason for participating in a study abroad program will demonstrate greater overall intercultural development as measured at the conclusion of the semester (pre-test to post-test) than those who participate to satisfy entertainment goals.

H5: $\quad$ Students having career development goals as their reason for participating in a study abroad program will demonstrate greater overall intercultural development as measured at the conclusion of the semester (pre-test to post-test) than those who participate to satisfy entertainment goals.

\section{Results}

\section{Motivation to Study Abroad Questionnaire}

As can be seen in Exhibit 3, World Enlightenment and Personal Growth are the highest rated of the motivations for studying abroad. The students' motivations for Entertainment is significantly lower than the other three scales. While this may be an encouraging finding for schools sending students on study abroad programs and for the providers of those programs, some caution should be exercised. It is quite likely that students choosing to participate in a study abroad program may consciously or subconsciously be unwilling to admit their true reasons for choosing to participate. However, our focus is on the changes in the students' intercultural development given their motivations to study abroad. Consequently, the absolute scores for the students' motivations are not as important as the relative changes in their intercultural development over the duration of the study abroad program. 
Exhibit 3. Results for the four factors of the MSA

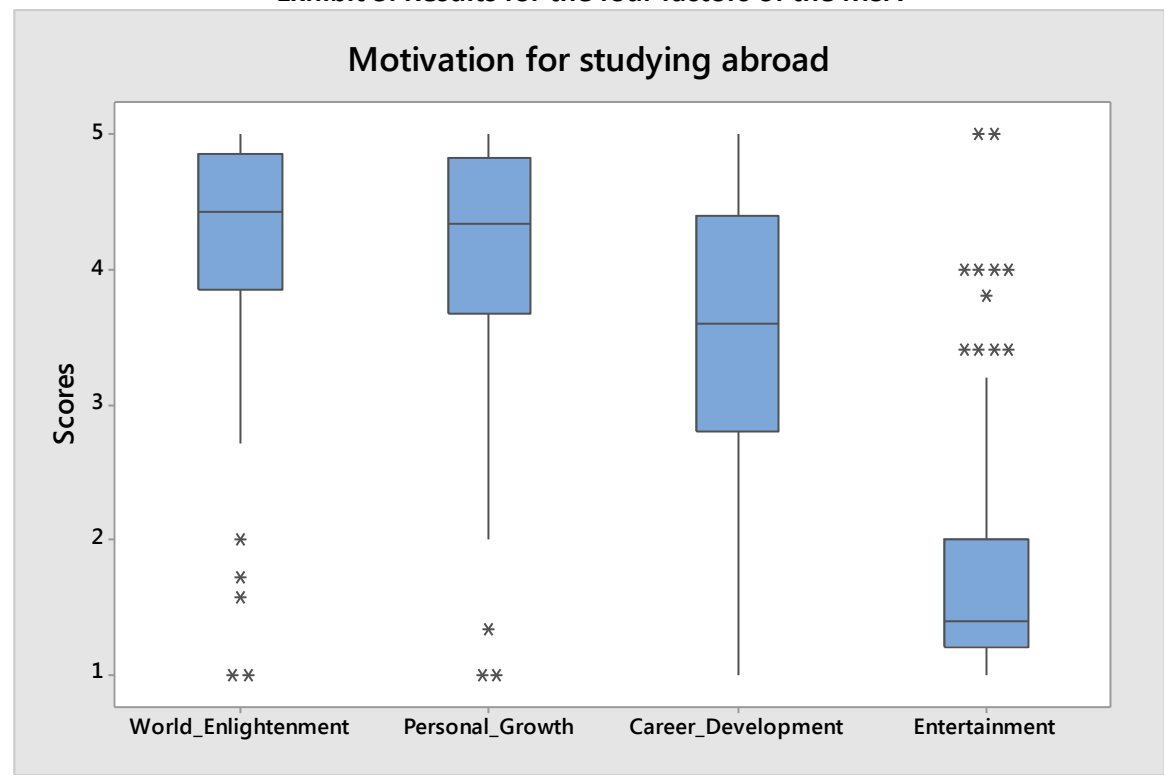

\begin{tabular}{|c|c|c|c|c|}
\hline Dimension & $\underline{\mathrm{n}}$ & Mean & Std. dev. & Grouping \\
\hline World enlightenment & $\overline{3} 52$ & 4.28 & 0.68 & $\bar{A}$ \\
\hline Personal growth & 352 & 4.17 & 0.76 & A \\
\hline Career development & 352 & 3.53 & 1.00 & B \\
\hline Entertainment & 352 & 1.70 & 0.68 & C \\
\hline
\end{tabular}

Results of repeated measures ANOVA on the four MSA factors is shown above.

Means that do not share a letter are significantly different. For example, there were no significant difference between World Enlightenment and Personal Growth, but these means were both significantly different from Career Development and Entertainment.

\section{Motivation to Study Abroad and Gender Differences}

As shown in Exhibit 4, male students in the study scored significantly lower than females in their motivation to study abroad to gain World Enlightenment and Personal Growth. There were no significant differences between males and females on the Career Development and Entertainment motivation scales. The absence of any difference on the Entertainment scale was unexpected, given the conventional wisdom that males seek out entertainment options to a greater degree than females. Based on these results, neither males nor females admit to being particularly motivated to study abroad for the sake of entertainment and females show no less desire for entertainment than males.

Exhibit 4. Motivation to Study Abroad and Gender Differences

\begin{tabular}{|c|c|c|c|c|c|c|c|c|}
\hline & \multicolumn{2}{|c|}{ World Enlightenment } & \multicolumn{2}{|c|}{ Personal Growth } & \multicolumn{2}{|c|}{ Career Development } & \multicolumn{2}{|c|}{ Entertainment } \\
\hline & Mean & Std. dev. & Mean & Std. dev. & Mean & Std. dev. & Mean & Std. dev. \\
\hline Males $\quad(n=57)$ & 4.03 & 0.84 & 3.93 & 0.94 & 3.48 & 1.14 & 1.79 & 0.67 \\
\hline Females $(n=295)$ & 4.33 & 0.64 & 4.22 & 0.72 & 3.54 & 0.97 & 1.68 & 0.68 \\
\hline$p$-value & 0.015 & & 0.031 & & 0.702 & & 0.264 & \\
\hline
\end{tabular}

\section{Motivation to Study Abroad and Language of Instruction}

While some might suspect that students seeking entertainment would be more likely to select programs with English as the language of instruction and would choose to live with other US students, because these options would be less challenging and therefore have more time and opportunity for non-academic pursuits, we found little support for this supposition. Exhibit 5 shows that students 
whose courses were delivered in English did not have significantly higher entertainment scores than those whose courses were given in a foreign language. In fact, no significant differences were found between any of the four dimensions of the MSA and language of instruction.

Exhibit 5. MSA Entertainment scores and Language of Instruction

\begin{tabular}{llll|}
\hline Language of instruction & $\underline{\mathrm{n}}$ & $\underline{\text { Mean }}$ & $\underline{\text { Std. dev. }}$ \\
English & 248 & 1.677 & 0.638 \\
Non-English & 76 & 1.689 & 0.732 \\
\hline P-Value $=0.897$ & & & \\
\hline
\end{tabular}

Not surprisingly, a significant relationship was found between the student's major and language of instruction. Those students majoring in a foreign language were far less likely to take classes taught in English. English was the language of instruction for $90 \%$ of Business and Communications students, $70 \%$ of Social Science, Art/Music, Science students, and $62 \%$ of International students. Only 19\% of Language students took classes with English as the language of instruction.

As shown in Exhibit 6, a significant relationship was found between living accommodations and scores on the MSA entertainment dimension; students choosing homestay accommodations had significantly lower entertainment scores than those living solely with other US students or with US and non-US students.

Exhibit 6. One-way ANOVA results for Entertainment and Living Accommodations

\begin{tabular}{|c|c|c|c|}
\hline Living arrangements & $\underline{\mathrm{n}}$ & Mean & Grouping \\
\hline Integrated (US and non US students) & 88 & 1.85 & A \\
\hline With US students & 140 & 1.74 & A \\
\hline Homestay & 94 & 1.47 & B \\
\hline
\end{tabular}

p-value for the ANOVA $<0.001$

Means that do not share a letter are significantly different at the 0.05 level of significance.

\section{Hypothesis Results}

Below is a discussion of the test results for the five hypotheses for this research. While we found some significant differences, we were surprised and disappointed by our failure to confirm more of our expectations.

H1: The choice of a program destination will be associated with the student's motivation for studying abroad. We anticipate that students seeking entertainment will choose "less challenging" destinations than those motivated by a desire for world enlightenment.

As shown in Exhibit 7, the pattern of the means supports the hypothesis. Even though not all differences reach statistical significance, the very highest means are England, Ireland, Australia, and New Zealand, the countries in which US students are likely to feel most at home. Entertainment scores 
are lowest for students spending their study abroad experience in arguably the more challenging destinations of South and Central America. While the mean for South Africa is considerably lower than England, Ireland, Australia, New Zealand, and Europe, the sample size for that group is only seven, thus limiting our ability to find statistical significance.

Exhibit 7. MSA Entertainment scores and program location

\begin{tabular}{|lcccc|}
\hline Destination country & $\underline{\mathrm{n}}$ & $\underline{\text { Mean }}$ & & Grouping \\
England and Ireland & 98 & 1.80 & $\mathrm{~A}$ & $\mathrm{~A}$ \\
Australia and New Zealand & 12 & 1.78 & $\mathrm{~B}$ & $\mathrm{~B}$ \\
Europe (non-English speaking) & 209 & 1.70 & $\mathrm{~A}$ & $\mathrm{~B}$ \\
South Africa & 7 & 1.43 & & $\mathrm{~B}$ \\
South and Central America & 26 & 1.35 & & \\
\hline
\end{tabular}

$p$-value for the ANOVA $=0.037$

Means that do not share a letter are significantly different at the 0.05 level of significance. (See explanation in Exhibit 4)

H2: Students' post-GPI scores will be higher than their pre-GPI scores on the six dimensions of the GPI.

As shown in Exhibit 8, none of the post-GPI scores were significantly different from the preGPI scores. We were surprised by this result, given we had consistently found significant changes in our previous research using the GPI (Anderson \& Lawton, 2012). We can only speculate as to why no significant differences were found. One contributing factor may have been that the AIFS students in the present study began the program at a substantially higher level (an average of over three tenths of a point per scale on the five point scales) than did students in our previous studies. Thus, there was less room for the AIFS students to improve their scores on the GPI.

\section{Exhibit 8. Global Perspectives Inventory Results. Paired one-tailed t-tests}

\begin{tabular}{|l|l|l|l|l|l|l|}
\hline & \multicolumn{4}{|l|}{ Cognitive Domain } & \multicolumn{3}{|l|}{ Intrapersonal Domain } & \multicolumn{2}{l|}{ Interpersonal Domain } \\
Pre & Knowledge & Knowing & Identity & Affect & Social Responsibility & Social Interaction \\
Post & 3.71 & 3.69 & 4.12 & 3.90 & 3.70 & 3.89 \\
Difference & 3.73 & 3.69 & 4.15 & 3.90 & 3.70 & 3.90 \\
\hline
\end{tabular}

* None of the pre-post changes were statistically significant.

H3-5: Hypotheses 3 through 5 involved whether students motivated by goals of World Enlightenment, Personal Growth, and Career Development had greater intercultural development than students motivated by Entertainment goals.

Since we found no significant pre-post changes on any of the six dimensions of the GPI, Hypotheses 3 through 5 were not supported. In the absence of any significant gains in intercultural development by the students in this study, the questions raised by these hypotheses are left unanswered.

Why this study did not find gains in intercultural development, while other studies have, is an indication of our lack of knowledge concerning the factors that drive successful program outcomes. There are a myriad of factors that differentiate one program from another, such as program length, 
interventions (facilitation) by the program leaders. At this point in our study of overseas programs, we simply don't have sufficient research to guide us in evaluating why student gains in intercultural development may be realized in some cases, but not in others. But this highlights the need for continued research in this area.

\section{Relationships between Students' Motivations to Study Abroad and pre-GPI Scores}

While we were unable to find any association between motivations to study abroad and changes in cultural sensitivity, analysis did reveal a large number of significant relationships between motivations and the various dimensions of the GPI. It appears that the stronger the student's motivation for world enlightenment, personal growth, and career development, the higher his or her scores on the various dimensions of the GPI were likely to be at the beginning of the program. We found significant positive relationships between students' World Enlightenment scores and all dimensions of the GPI at the start of the program. All relationships were highly statistically significant (p-values less than 0.001) with Enlightenment scores able to explain as much as $18.5 \%$ of the variation in GPI scores.

Statistically significant relationships were found on five of the six dimensions of pre-GPI scores and Career Development and three of the six pre-GPI dimensions and Personal Growth. In every case, the higher the motivation score, the higher the GPI score. While the relationships were highly statistically significant, the relationships were able to explain less than $10 \%$ of the variation in pre-GPI scores.

The only MSA scale that showed little correlation with the pre-GPI scores was Entertainment; Entertainment scores were correlated with only the Cognitive Knowing scale of the GPI. This relationship was negative - students with higher entertainment scores were less likely to be knowledgeable of different cultures and their importance in a society's values.

\begin{tabular}{|c|c|c|c|c|c|c|c|c|}
\hline & $\begin{array}{l}\text { World En } \\
\text { p-value }\end{array}$ & $\begin{array}{l}\text { nlightenment } \\
\text { R-squared }\end{array}$ & $\begin{array}{l}\text { Personal } \\
\text { p-value }\end{array}$ & $\begin{array}{l}\text { Growth } \\
\text { R-squared }\end{array}$ & $\begin{array}{l}\text { Career D } \\
\mathrm{p} \text {-value }\end{array}$ & $\begin{array}{l}\text { evelopment } \\
\text { R-squared }\end{array}$ & $\begin{array}{l}\text { Entertair } \\
\text { p-value }\end{array}$ & $\begin{array}{l}\text { nment } \\
\text { R-squared }\end{array}$ \\
\hline Cognitive knowing & $<0.001$ & $3.71 \%$ & 0.505 & $0.00 \%$ & 0.712 & $0.00 \%$ & $<0.001$ & $4.34 \%$ \\
\hline Cognitive knowledge & $<0.001$ & $4.82 \%$ & 0.064 & $0.69 \%$ & $<0.001$ & $5.70 \%$ & 0.281 & $0.05 \%$ \\
\hline $\begin{array}{l}\text { Interpersonal social } \\
\text { interaction }\end{array}$ & $<0.001$ & $14.12 \%$ & $<0.001$ & $4.57 \%$ & $<0.001$ & $5.75 \%$ & 0.234 & $0.12 \%$ \\
\hline $\begin{array}{l}\text { Interpersonal social } \\
\text { response. }\end{array}$ & $<0.001$ & $18.54 \%$ & $<0.001$ & $6.12 \%$ & $<0.001$ & $3.14 \%$ & 0.810 & $0.00 \%$ \\
\hline Intrapersonal affect & $<0.001$ & $9.60 \%$ & 0.096 & $0.51 \%$ & 0.001 & $2.88 \%$ & 0.104 & $0.47 \%$ \\
\hline Intrapersonal identity & $<0.001$ & $9.52 \%$ & $<0.001$ & $4.95 \%$ & $<0.001$ & $8.99 \%$ & 0.630 & $0.00 \%$ \\
\hline
\end{tabular}

\section{Discussion and Conclusions}

The objective of this study was to examine the role played by a student's motivation to study abroad. The results of the study suggest that motivation is an important factor when investigating study abroad programs. Not only is motivation linked to the choice of a program destination (students with stronger entertainment motivations are more likely to choose less challenging destinations than those motivated to learn about the world or to seek personal growth), it also is related to the living 
arrangements selected - students with higher entertainment motivation are less likely to choose homestays, settings which are likely to more deeply immerse a student into the indigenous culture.

A major surprise and disappointment of this study was that no pre-post differences were found in GPI scores. This result was surprising because our previous research has consistently found improvements in cultural competence. (And our findings of pre-post changes echo the majority of studies reported in the literature.) Failure to find improvements was disappointing because we were unable to examine whether motivation was related to the magnitude of improvement in cultural competence. Our hypothesis going into the study was that students electing to study abroad to learn about the world or to experience personal growth would reap greater benefits from studying abroad than would those motivated by a desire for entertainment. Since we observed no significant pre-post changes in cultural competence, we were unable to test this hypothesis. While the lack of significant results are disappointing, they are, nevertheless, an important finding. Since research on intercultural development is at a relatively early stage of exploration, if we are to gain an understanding of the circumstances that contribute to cultural development, we must consider both those cases that do not yield significant gains as well as those that do. It is only through the investigation of findings at both ends of the spectrum that we will be able to discern what leads to success; it is this knowledge that will enable program providers and leaders to design programs that will produce optimal outcomes. One reassuring outcome of the present study is that, contrary to the conventional wisdom that a student's preoccupation with entertainment negatively impacts that student's intercultural development, we found little support for this supposition. This should provide some comfort for providers and faculty regarding why students choose to study abroad. It may well be that what is important is only that a student has a study abroad experience, not why they choose to participate in that experience.

Returning to the question of why we failed to observe pre-post changes, one factor that undoubtedly interferes with the ability to pick up gains in cultural competence relates to the state of the instrument used to measure cultural competence. Reliability scores for the GPI with our sample of students were quite low. (Cronbach's alpha scores ranged from 0.55 to 0.77 with a median of 0.68. While there is debate over the appropriate value for Cronbach's alpha, the values we found for the GPI are certainly quite low.) The ability to measure changes in any phenomenon is problematic with when the reliability of the instrument is only marginally acceptable. (Developing an instrument to measure a complex construct such as cultural competence is a difficult task. The authors of the GPI are continuously striving to improve its reliability and, in fact, a more current version of the instrument than that used in this study is now available.)

Another possible explanation for the failure of this study to detect gains from the study abroad experience may have to do with the sample used in this study. The "pre" scores for the sample of AIFS students in this study were considerably higher on all dimensions of the GPI than those of students in our previous studies. In fact, scores on three of the six GPI scales were 3.89 or higher on a five point scale. With such high starting points, it is much more difficult to achieve significant gains.

In any event, for whatever reason, we were stymied in our attempt to see if students with differing motivations experienced differential gains from the study abroad programs they chose. However, we did observe that at the beginning of their programs when the "pre" measures were taken, "noble" 
motivations for embarking on a study abroad program (i.e., a desire to learn about the world, to achieve personal growth, and to develop one's career) were positively correlated with cultural competence. Conversely, a desire for entertainment was negatively correlated with cultural competence. In other words, students with higher levels of cultural competence tended to have higher motivation scores on three of the four dimensions of the MSA, World Enlightenment, Personal Growth, and Career Development.

This study is a first step in examining the link between motivation and the various elements of study programs; clearly more work must be done. Given the results of this study, it appears that motivation to study abroad is an important dimension to consider in future research efforts. As the tools for measuring the impact of a study abroad program are further developed and refined, we believe that we will gain greater insight into what program characteristics will attract students and what program features will optimize the gains that students realize from the experience.

\section{References}

AACSB International Eligibility Procedures and Accreditation Standards for Business Accreditation (2012) Retrieved August 2012, http://www.aacsb.edu/accreditation/standards-busn-jan2012.pdf

Association to Advance Collegiate Schools of Business (2007) Eligibility Procedures and Accreditation Standards for Business Accreditation, pgs. 12 \& http://www.aacsb.edu/accreditation/process/documents/AACSB STANDARDS Revised Jan07 Ann otated.pdf

Anderson, P.H. \& Lawton, L. (2012). Intercultural Development: Study Abroad vs. On-campus Study. Frontiers: The Interdisciplinary Journal of Study Abroad, 21, 86-108.

Anderson, P.H., Lawton, L., Rexeisen, R.J., and Hubbard, A.C., (2006) Short-Term Study Abroad and Intercultural Sensitivity: A Pilot Study, International Journal of Intercultural Relations, 30 (4), 457- 469.

Bennett, J.M. (2011). Developing Intercultural Competence for International Education Faculty and Staff. 2011 AIEA Conference. Retrieved April 13, 2015 from http://www.intercultural.org/documents/competence handouts.pdf

Bennett, M.J. (2010). A short conceptual history of intercultural learning in study abroad. In W.W. Hoffa \& S.C. DePaul (Eds.), A history of U.S. study abroad: 1965-present (pp. 419-449). Lancaster, PA: Frontiers: The Interdisciplinary Journal of Study Abroad

Braskamp, L.A., Braskamp, D. C. \& Engberg, M.E. (2013). Global Perspective Inventory: Its Purpose, Construction, Potential Uses, and Psychometric Characteristics. Retrieved from https://gpi.central.edu/supportDocs/manual.pdf

Braskamp, L.A., Braskamp, D. C. Merrill, K. C. \& M. Engberg (2010). Global Perspective Inventory. Retrieved September 1, 2010 , from https://gpi.central.edu/supportDocs/manual.pdf

Braskamp, L.A., Braskamp, D.C., \& Merrill, K.C. (2009). Assessing progress in intercultural learning and development of students with education abroad experiences. Frontiers: The Interdisciplinary Journal of Study Abroad, 18, 101-118.

Braskamp, L.A., Braskamp, D.C., \& Merrill, K.C. (2008). Global Perspectives Inventory (GPI): Its purpose, construction, potential uses, and psychometric characteristics. Retrieved January 12, 2010 from http://gpi.central.edu/supportDocs/manual.pdf.

Engle, L. and Engle, J. (2004). Assessing Language Acquisition and Intercultural Sensitivity Development in Relation to Study Abroad Program Design. Frontiers: The Interdisciplinary Journal of Study Abroad, 10, 219-236.

Earnest, G. W. (2003). Study abroad: A powerful new approach for developing leadership capacities. Journal of Leadership Education, 2, 2-14. 
Franklin, K. (2010). Long-term career impact and professional applicability of the study abroad experience. Frontiers: The Interdisciplinary Journal of Study Abroad, XIX, 169-90.

Gillespie, J. (2002). Colleges Need Better Ways to Assess Study abroad Programs. The Chronicle of Higher Education. July 5, 2002.

Greenholtz, J. (2000). Assessing cross-cultural competence in transnational education: The Intercultural Development Inventory. Higher Education in Europe, 25(3), 411-416.

Hammer, M.R. and Bennett, M.J. (2002). The Intercultural Development Inventory (IDI) Manual. Portland, OR: Intercultural Communication Institute.

Hammer, M. R., Bennett, M. J., \& Wiseman, R. (2003). Measuring intercultural sensitivity: The intercultural development inventory. International Journal of Intercultural Relations, 27, 421-443.

Higher Learning Commission (2012) Overview of accreditation, standards, 4c, p6. (http://www.ncahlc.org/Information-for-Institutions/criteria-for-accreditation.html)

Higher Learning Commission (2007), Overview of Accreditation, Standards, 4c, p. 6, http:/ / www.ncahlc.org/index.php?option=com_docman\&task=cat_view\&gid=33\&Itemid=23 6

Hoffa, W.W., (2007). A bistory of U.S. study abroad: Beginning to 1965. A Special Publication of Frontiers: The Interdisciplinary Journal of Study Abroad and the Forum on Education Abroad

Hoffa, W.W. \& DePaul, S.C. (Eds.) (2010), A history of U.S. study abroad: 1965-present. A Special Publication of Frontiers: The Interdisciplinary Journal of Study Abroad and the Forum on Education Abroad

Institute of International Education. (2014). "Duration of U.S. Study Abroad, 2000/01-2012/13." Open Doors Report on International Educational Exchange. Retrieved from http://www.iie.org/opendoors

The Institute for International Education (2012). Open Doors Report. Retrieved from www.iie.org/opendoors.

The Institute for International Education (2013). Open Doors Report. Retrieved from www.iie.org/Research-and-Publications/Open-Doors/Data/US-Study-Abroad

Internationalization of US Higher Education, American Council on Education Report (2000).

Preliminary Status Report 2000. Retrieved from

http://www.nyu.edu/classes/jepsen/internationalreport2000.pdf

Kelly, G. (1963). A Theory of Personality. New York: Norton.

Landis D. and Bhagat, R.S. (1996). Handbook of Intercultural Training ( $2^{\text {nd }}$ ed.) Thousand Oaks, CA. Sage.

Lincoln Commission's (2005). Report on Global Competence and National Needs: One Million Students Studying Abroad. http://www.nafsa.org/ / Document/ /lincoln commission report.pdf

Medina-López-Portillo, A. (2004). Intercultural Learning Assessment: The Link between Program Duration and the Development of Intercultural Sensitivity. Frontiers: The Interdisciplinary Journal of Study Abroad, 10,179-199.

Paige, R. M., Cohen, A. D. and Shively, R. L. (2004). Assessing the impact of a strategies-based curriculum on language and culture learning abroad, Frontiers: The Interdisciplinary Journal of Study Abroad, 10,253-276.

Paige, R.M. and Vande Berg, M. (2012) Why students are and are not learning abroad. In M. Vande Berg, R.M. Paige, and K.H. Lou (Eds), Student Learning Abroad: What our students are learning, what they're not, and what we can do about it. Sterling, VA: Stylus Publishing, LLC.

Patterson, P. (2006) Effect of Study Abroad in Intercultural Sensitivity, Unpublished Doctoral Dissertation. (University of Missouri, Columbia, MO).

Rexeisen, R.J. and Al-Khatib, J.A. (2009) Assurance of learning and study abroad: A case study. Journal of Teaching in International Business, 20(3), 192-207. Doi 10.1080/08975930903099077

Rexeisen, R.J. (2012-2013) Study abroad and the Boomerang Effect: The end is only the beginning. 
Frontiers: The Interdisciplinary Journal of Study Abroad, 22l, 179-199.

Rexeisen, R. Anderson, P. Lawton, L. and Hubbard, A. (Fall, 2008) Study Abroad and Intercultural Development: A Longitudinal Study. Frontiers: The Interdisciplinary Journal of Study Abroad, 17, 1-20.

Roy, P., Wandschneider, E., and Steglitz, I., (2014) Assessing Education Abroad Outcomes: A Review of Three Instruments. Downloaded on 31 March 2015 from http://studyabroad.isp.msu.edu/research/documents/assessing ed abroad outcomes.pdf

Stebelton, M., Soria, K. and Cherney, B. (2012-2013) The High Impact of Education Abroad: College Students' Engagement in International Experiences and the Development of Intercultural Competencies. Frontiers: The Interdisciplinary Journal of Study Abroad, 22, 1-24.

Stroud, A., (2010) Who Plans (Not) to Study Abroad? An Examination of U.S. Student Intent. Journal of Studies in International Education, 14 (5), 491-507.

Vande Berg, M. (2001). The assessment of learning outcomes in study abroad. International Educator, $10(2), 31$.

Vande Berg, M., Connor-Linton, J., and Paige, R.M. (2009) The Georgetown Consortium Project: Interventions for Students Living Abroad. Frontiers: The Interdisciplinary Journal of Study Abroad, 18, $1-75$. 